\title{
THE CONTROL OF FIRING PATTERN IN NIGRAL DOPAMINE NEURONS: SINGLE SPIKE FIRING ${ }^{1}$
}

\author{
ANTHONY A. GRACE ${ }^{2}$ AND BENJAMIN S. BUNNEY ${ }^{3}$ \\ Departments of Psychiatry and Pharmacology, Yale University School of Medicine, New Haven, Connecticut 06510
}

Received February 14, 1984; Revised May 14, 1984; Accepted June 6, 1984

\begin{abstract}
Dopamine (DA) neurons have been recorded in vivo in four states of activity: (1) hypcrpolarized, nonfiring; (2) single spike firing; (3) burst firing; and (4) depolarization inactivation. Nonfiring DA neurons can be made to fire by iontophoretic application of the excitatory substances glutamate and cholecystokinin, or by depolarizing current injection. Spontaneously active DA cells typically fire in a slow $(3$ to $8 \mathrm{~Hz})$ irregular pattern. In vivo intracellular recordings revealed that this pattern is sustained by the alternation of two currents: a spontancously occurring slow depolarization ( $13 \pm 3 \mathrm{mV}$ amplitude, $78 \pm 10 \mathrm{msec}$ duration) which brings the membrane potential of the DA cell to spike threshold $(-42 \mathrm{mV})$, and an afterhyperpolarization mediated by a calcium-activated potassium conductance $\left(I_{\mathrm{K}(\mathrm{Ca})}\right)$. The slow depolarization is a pacemaker-like conductance, with a rate of rise proportional to the membrane potential. 'The regular pacemaker pattern of the spontaneously occurring slow depolarization is interrupted by the $I_{\mathrm{K}(\mathrm{Ca})}$ which appears to be triggered by calcium entry during the action potential. Thus, intracellular injection of the calcium chelator EGTA will cause DA cells to fire in a regular, pacemaker pattern. The $I_{\mathrm{K}\left(\mathrm{C}_{2}\right)}$ is observed after single spikes and trains of spikes with the amplitude of the afterhyperpolarization being proportional to the number of spikes in a train. Both the afterhyperpolarization and the firing accommodation observed during depolarizing current injection can be blocked by intracellular injection of the calcium chelator EGTA.
\end{abstract}

Dopamine (DA) cells have been observed in four states of activity when recorded extracellularly in chloral hydrate-anesthetized or gallamine-paralyzed rats. Two inactive states have been observed and have been hypothesized to be due to either inhibition resulting in a hyperpolarized, inactive cell (Bunney and Grace, 1978) or, following specific manipulations, hyperexcitation resulting in a depolarization blocked state (Bunney and Grace, 1978; Braszko et al., 1981; Skirboll et al., 1981). Spontaneously discharging DA cells can also exist in different states of activity. Two firing patterns have been observed: (1) a slow, single spiking pattern, and (2) burst firing (Bunney et al., 1973; Grace and Bunney, 1983a, c, 1984a, b). The single spiking pattern is characterized by trains of spikes which discharge at steady but irregular intervals, and it is the typical firing pattern of the majority of DA cells encountered in untreated, anesthetized rats. In this paper, we explored the factors involved in mediating this firing pattern using intracellular and extracellular recording techniques. In the companion paper (Grace and Bunney, 1984b) we describe factors modulating the

\footnotetext{
${ }^{1}$ We thank Chen-Lun Pun for laboratory assistance and Suzanne Mulready for manuscript preparation. This work was supported in part by United States Public Health Service Grants MH-28849 and MH25642, the Robert Alwin Hay Fund for Schizophrenia Research, and the State of Connecticut.

${ }^{2}$ Present address: Department of Physiology and Biophysics, New York University Medical Center, 550 First Avenue, New York, NY 10016.

${ }^{3}$ To whom correspondence should be addressed.
}

transition from this single spike pattern to a burst firing pattern. An abstract of these data has been presented previously (Grace and Bunney, 1983c).

\section{Materials and Methods}

Animals and surgical procedure. All experiments were performed in vivo on Sprague-Dawley albino male rats (200 to $300 \mathrm{gm}$ ) obtained from Charles River Breeding Laboratory. Intracellular and extracellular recordings were obtained from identified substantia nigra DA cells, as previously described (Grace and Bunney, 1983a). Briefly, rats were anesthetized with chloral hydrate ( $400 \mathrm{mg} / \mathrm{kg}$, i.p.), with supplemental anesthetic administered via a lateral tail vein. In one set of experiments, unanesthetized, gallamine-paralyzed rats were used to control for anesthetic effects. This was done by initially anesthetizing the rats with a short-acting inhalation ancsthetic (halothanc) and infiltrating pressure points and incision sites with a long-acting local anesthetic, mepivocaine hydrochloride. A tracheotomy was then performed, and a breathing cannula was implanted prior to gallamine administration, as previously described (Bunney and Grace, 1978). Rats were mounted in a stereotaxic apparatus, and body temperature was monitored and maintained by a thermostatically controlled electric heating pad. A hole was drilled overlying the substantia nigra ( $1900 \mu \mathrm{m}$ anterior; 2200 $\mu \mathrm{m}$ lateral, according to the atlas of König and Klippel, 1970), and units were recorded in the zona compacta region $(6500$ to $7500 \mu \mathrm{m}$ ventral to the brain surface). All surgical procedures were carried out in strict accordance with Guiding Principles in the Care and Utse of Animals approved by the Council of the American Physiological Society.

Extracellular recording. Extracellular recording electrodes were pulled from glass tubing ( $2 \mathrm{~mm}$ outside diameter) containing a few strands of fiberglass to aid in filling (Tasaki et al., 1968). The electrodes were filled with $2 \mathrm{M} \mathrm{NaCl}$ containing $2 \%$ pontamine sky blue, and they had an impedance of 6 to 12 megohms measured at $1000 \mathrm{~Hz}$. DA cells 
were identified according to previously established criteria of waveform, firing rate, firing pattern, and location (Bunney et al., 1973; Guyenet and Aghajanian, 1978; Grace and Bunney, 1980, 1983a). At the end of each experiment, a $30-\mu \mathrm{A}$ negative current was passed through the electrode for $10 \mathrm{~min}$ in order to eject a small quantity of dye from the pipette tip. By this marking procedure, the recording site could later be verified histologically (Thomas and Wilson, 1965).

Spikes were counted by means of a time and amplitude window discriminator and were analyzed in three ways: (1) 10-sec spike rate histograms were generated on a chart recorder, (2) spikes were digitized and stored on a Nicolet digital oscilloscope, and (3) on-line and offline analyses of spike patterns were performed using a PDP-11/34 minicomputer.

Microiontophoresis. Drugs were applied by direct microiontophoresis to activate silent cells and test their drug sensitivity. Microiontophoresis was done as previously described (Grace and Bunney, 1979). Briefly, microiontophoretic pipettes were pulled from five-barrel micropipettes. The center barrel was filled with $2 \mathrm{M} \mathrm{NaCl}$ with $2 \%$ pontamine sky blue for extracellular recording and marking of the recording site. Three of the outer barrels were filled with either sodium glutamate $(0.2 \mathrm{M}, \mathrm{pH} 8)$ or dopamine hydrochloride $(0.1 \mathrm{M}, \mathrm{pH} 4)$. The fourth outer barrel was filled with $4 \mathrm{M} \mathrm{NaCl}$ for automatic current balancing, and drugs were retained with appropriate backing currents. Drugs were applied for 1 min before testing to allow for "warmup" effects (Bloom, 1974).

Intracellular recording. Intracellular recording electrodes were pulled from Omegadot tubing ( 1.5 or $2.0 \mathrm{~mm}$ outside diameter) on a modified Narishige vertical electrode puller. 'I'he electrodes were filled with either potassium acetate $(3 \mathrm{M}, \mathrm{pH} 7.0)$ or ethylene glycol bis $(\beta$-aminoethylether)- $N, N^{\prime}$-tetraacetic acid (EGTA, $0.1 \mathrm{M}$ in $3 \mathrm{~m}$ potassium acetate). The EGTA solution was allowed to diffuse into the impaled cells for periods of $20 \mathrm{~min}$ to $1.5 \mathrm{hr}$. Intracellular current injection was done across the bridge circuit of a W-P Instruments model 707 intracellular preamplifier. Animals were prepared as described above, and all recordings were obtained from identified DA neurons. Only stable DA cells were recorded, with stable penetration defined as: (1) action potentials of at least $55 \mathrm{mV}$ when they occur singly, (2) resting potentials of at least $55 \mathrm{mV},(3)$ the ability to fire multiple spikes with depolarizing current injection, and (4) demonstration of a stable input resistance. Intracellular waveforms were collected using: (1) a Grass Kymograph camera combined with a Tektronix oscilloscope, (2) a Nicolet digital oscilloscope with floppy disk storage for off-line computer analysis, and (3) an eight-channel Hewlett-Packard FM tape recorder for off-line analysis of firing patterns.

\section{Results}

In both chloral hydrate-anesthetized and gallamine-paralyzed rats, DA cells were found to be either firing spontaneously or nonfiring. The nonfiring DA cells could be activated during extracellular recording by intravenous haloperidol administration (Bunney and Grace, 1978) or by iontophoresis of the excitatory neurohumor glutamate $(N=10$; Fig. 1$)$. DA cells made to fire in this manner would cease activity when glutamate ejection was terminated and could be inhibited by coiontophoresis of DA (Fig. $1 B$ ). Observed intracellularly, these spontaneously inactive DA cells typically had a higher resting potential $(\sim-65$ to $-75 \mathrm{mV})$ compared to those firing spontaneously.

Spontaneously discharging nonburst- and burst-firing DA cells recorded extracellularly typically fired in a slow, irregular pattern at an average rate of $4.5 \pm 1.7 \mathrm{~Hz}$ (mean $\pm \mathrm{SD}$, range 0.2 to $10.8 \mathrm{~Hz}, N=597$; Fig. 2). DA cells firing below $1 \mathrm{~Hz}$ or above $9 \mathrm{~Hz}$ were rarely encountered. Nonbursting DA cells were found to have interspike intervals with a near normal distribution around 200 to $250 \mathrm{msec}$ (Fig. $3 A$ ), whereas burst-firing DA cells typically showed a bimodal distribution (Fig. $3 B$ ).

As previously reported, intracellular recordings revealed that DA neuron spikes are triggered by a slow depolarization preceding the action potential and are followed by an afterhyperpolarization (AHP) delaying the onset of the next slow depolarization (Grace and Bunney, 1983b). 'The alternation of these two components appears to underly the single spiking pattern
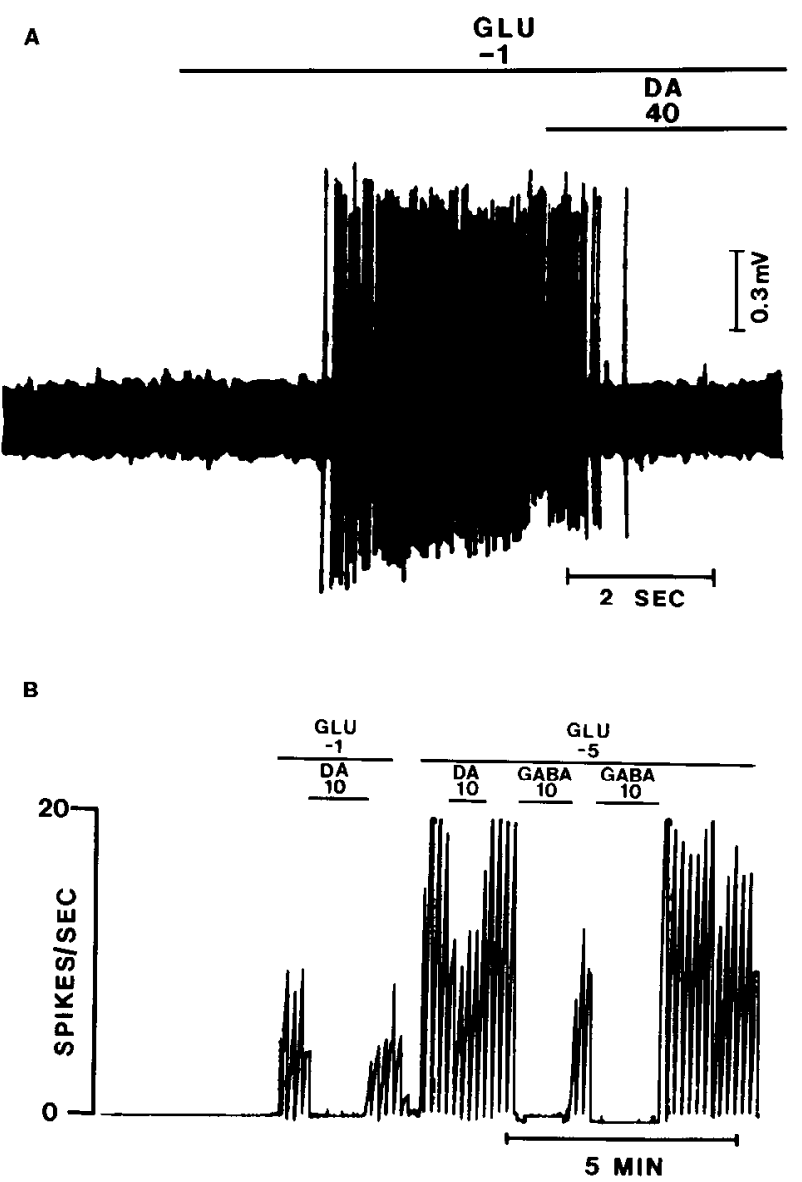

Figure 1. A, Oscilloscope tracing showing activation of a silent DA neuron by iontophoretic application of the excitatory amino acid glutamate $(G L U)$ during extracellular recording. This neuron can be inhibited by co-iontophoresis of dopamine $(D A) . B$, Rate histogram depicting the activation of a nonfiring DA neuron by iontophoretic glutamate. Silent DA neurons can be made to fire action potentials by iontophoretic application of the excitatory amino acid glutamate. Coiontophoresis of DA will still inhibit DA cells activated by glutamate. Furthermore, cessation of glutamate iontophoresis will cause the DA cell to revert to a silent state, although on occasion the DA cell will remain active following termination of the iontophoresis (not shown). Drugs ejected at bars. The numbers above the bars represent ejection current in nanoamperes.

of DA cell firing and, therefore, each of these components was studied in detail.

Slow depolarization. The slow depolarization preceding spike discharge occurs in all spontaneously firing DA cells observed intracellularly. This slow, pacemaker-like depolarization begins an average of $78 \pm 40 \mathrm{msec}$ before the spike and attains an average amplitude of $13.8 \pm 3.2 \mathrm{mV}$ (mean $\pm \mathrm{SD}, N=70$ ). Thus, the slow depolarization bridges the voltage difference between the resting membrane potential (average $=55 \pm 2.9$ $\mathrm{mV}, N=30$ ) and the comparatively high spike threshold (average $=41 \pm 4.2 \mathrm{mV}, N=30$; Fig. 4).

The slow depolarization appears to be responsible for the rclatively long interspike intervals observed for spontaneously discharging DA cells. Furthermore, evidence indicates that this slow depolarization may be voltage dependent, as it can be triggered in a nonfiring or slowly firing DA cell by a depolarization subthreshold to spike generation ( $N=20$; Fig. $5 A$ ). In addition, a short depolarizing pulse will initiate the slow depolarization, and a short hyperpolarizing pulse will reset the slow depolarization back to resting membrane potential and thus delay firing of the spike ( $N=15$; Fig. $5, B$ and $C)$. Intracellular injection of depolarizing current increases the firing rate of 
Figure 2. Firing rate histogram of DA neurons recorded extracellularly. DA cells typically fire at a rate of 4 to $5 \mathrm{~Hz}$, with very few cells firing below $1 \mathrm{~Hz}$ or above $9 \mathrm{~Hz}$.
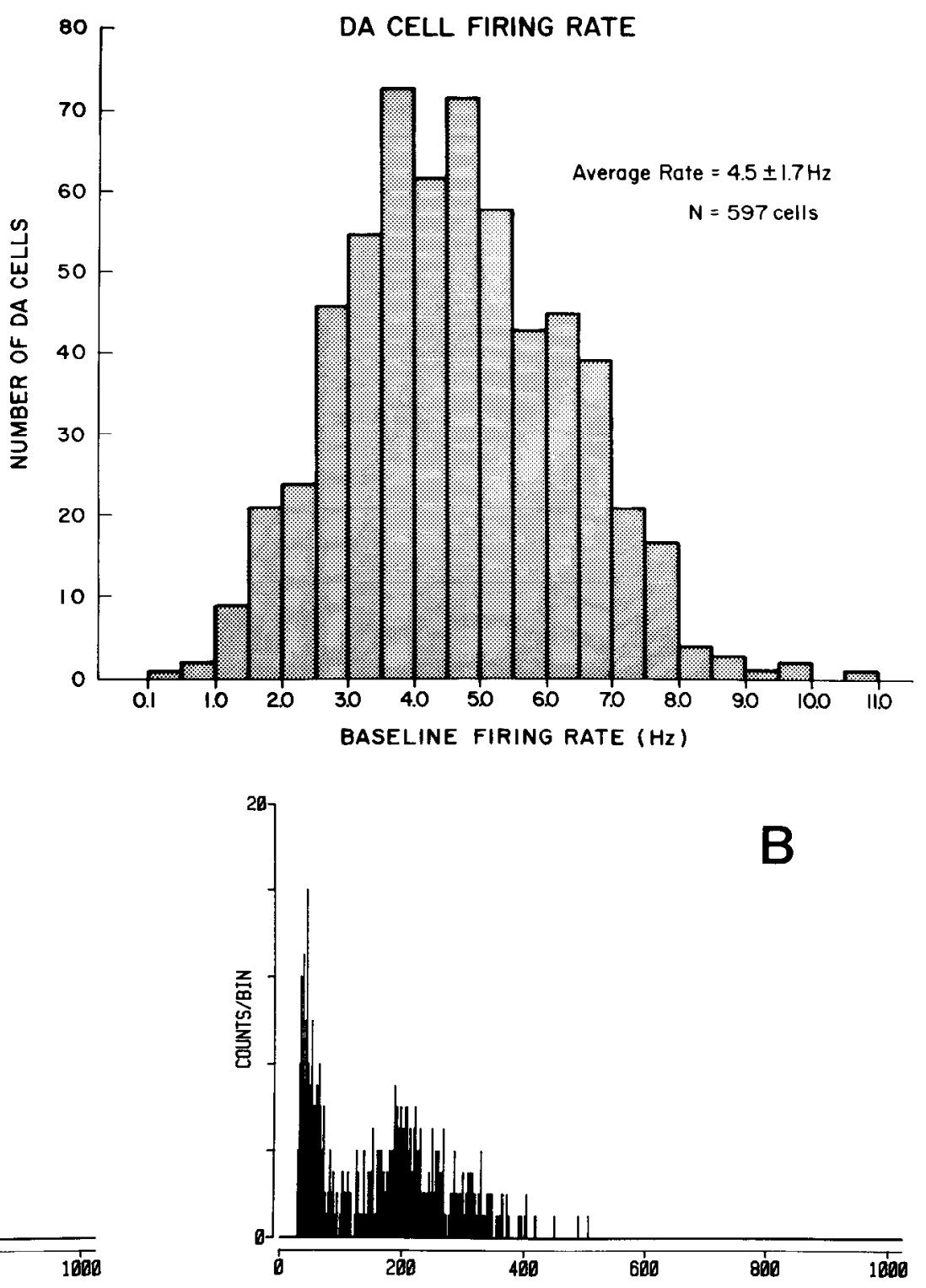

Figure 3. Interspike interval histograms of single spiking and burst-firing DA cells. $A$, When DA cells fire in a single spiking, nonbursting mode, the interspike intervals of the spike trains are typically distributed unimodally around an interval of 200 to 250 msec. $B$, Burst-firing DA neurons, on the other hand, typically show bimodal distributions of interspike intervals. The early peak (below $100 \mathrm{msec}$ ) represents the interspike intervals of the spikes contained within bursts, whereas the later peak (above 100 msec) corresponds to the longer intervals occurring between bursts or non-burst-related spikes.

Figure 4. DA cell action potentials arise from slow depolarizations. The slow depolarization bridges the voltage difference between the resting membrane potential $(-58 \mathrm{mV})$ and the atypically high initial segment spike threshold $(-42 \mathrm{mV})$ characteristic of DA neurons. The action potential triggered by the slow depolarization is followed by an AHP which brings the membrane potential back to base line levels prior to the onset of the next slow depolarization.

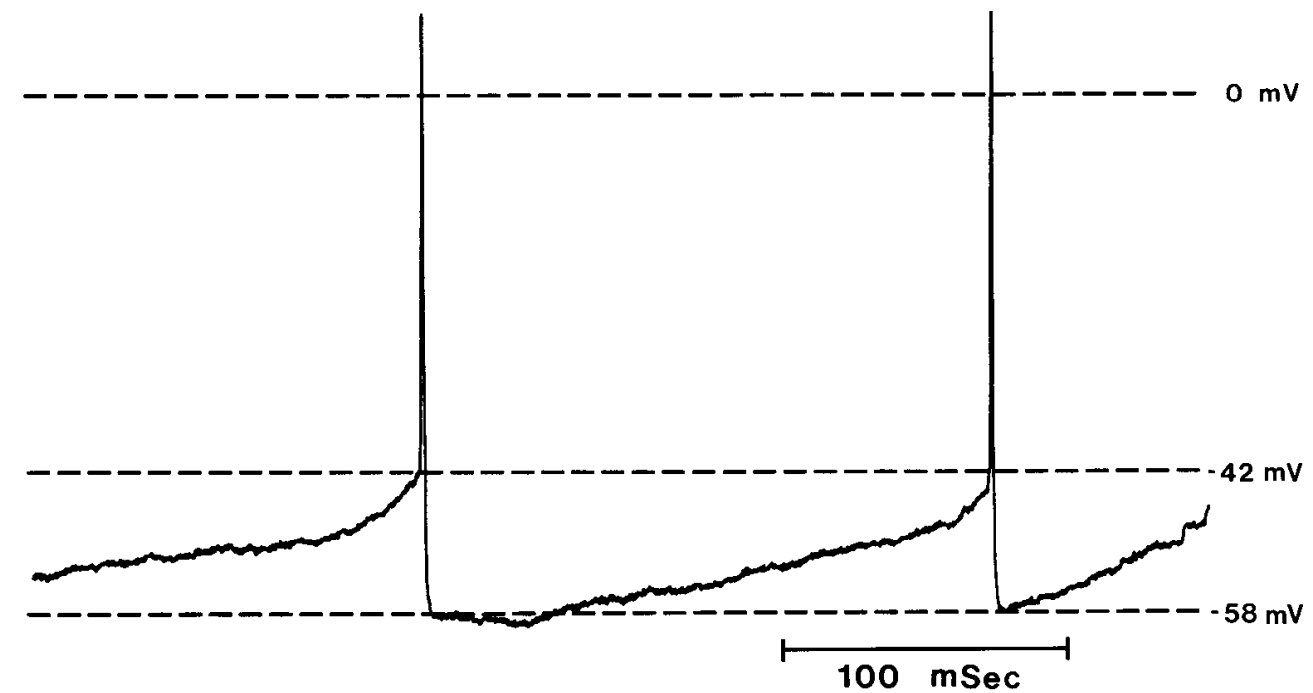




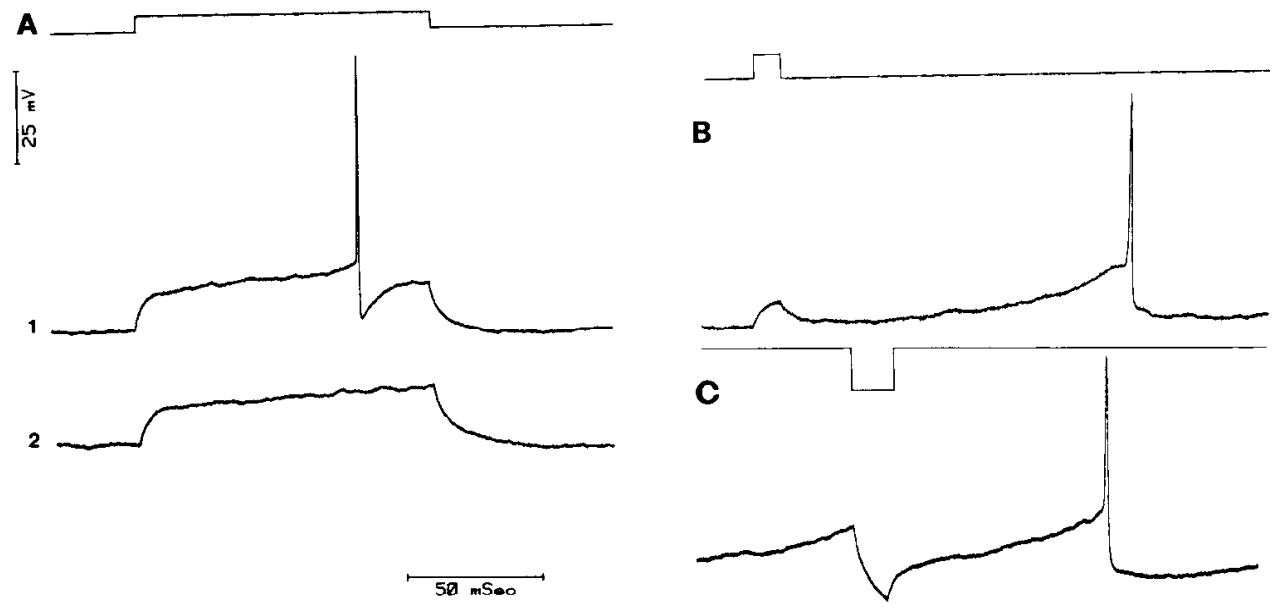

Figure 5. Dependence of the slow depolarization on membrane potential. A, Slow depolarizations, besides occurring spontaneously, can be triggered in nonfiring DA cells by intracellular injection of low levels of depolarizing current. $A_{1}$, Intracellular injection of depolarizing current $(0.4 \mathrm{nA})$ elicits a slow depolarization leading to an action potential in a DA cell exhibiting no spontaneous activity. $A_{2}$, Repetition of this threshold depolarizing pulse triggers a slow depolarization, which in this case does not reach spike threshold. The slow depolarization in the absence of an action potential decays passively to base line membrane potential at the termination of the depolarizing pulse. $B$, Initiation of a slow depolarization in a nonfiring neuron by a short pulse of depolarizing current $(0.6 \mathrm{nA})$. C, The slow depolarization is also reset by injection of short pulses of hyperpolarizing current (1.0 nA, injected just prior to the point where the membrane potential reaches spike threshold in the figure), demonstrating their voltage-dependent activation and deactivation.

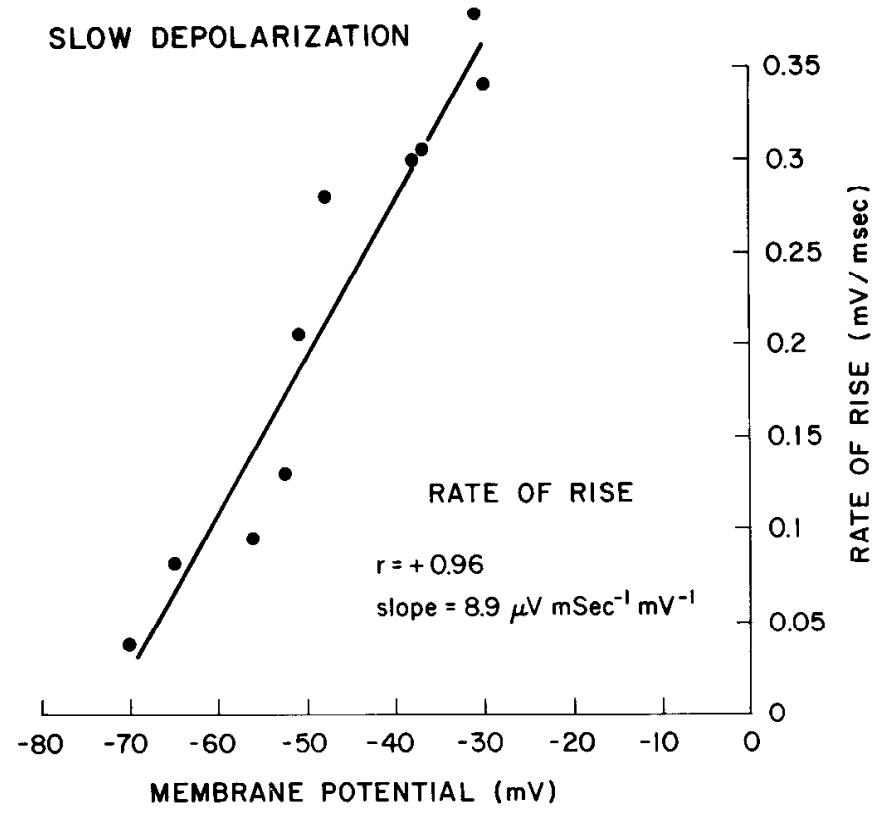

Figure 6 . The effects of altering the membrane potential on the rate of rise of the slow depolarization preceding spontaneous spike generation. As the spontaneously firing DA cell was depolarized from rest, the rate of rise of the slow depolarization was observed to increase. This was accompanied by a decreased interspike interval and hence a greater rate of spike discharge.

spontaneously discharging DA cells. This increased rate is reflected by a proportional increase in the average rate of rise of the slow depolarization at the more depolarized levels $(N=$ 6; Fig. 6). However, the increased rate of rise of the slow depolarization is partially counterbalanced by an increase in the spike threshold ( $N=8$; Fig. 7). Measurement of the input resistance taken during the slow depolarization and immediately following the spike are difficult to perform accurately, due to the long membrane time constant and the inactivation of the slow depolarization by hyperpolarizing current pulses. However, in light of the importance of this determination in evaluating the nature of the slow depolarization as well as the AHP which occurs during DA cell action potential generation, an attempt was made to estimate the input resistance changes accompanying these phenomena. Thus, in order to obtain a rough estimate of the relative input resistance changes occurring before and after a spike, a series of brief ( 5 to $10 \mathrm{msec}$ ) low amplitude ( 0.1 to $0.3 \mathrm{nA}$ ) constant current hyperpolarizing pulses were injected intracellularly into DA neurons, and input resistance measurements were calculated, to obtain some information concerning the conductance changes occurring during spiking. Although this methodology is insufficient for a careful, well controlled investigation of the input resistance changes occurring during these processes, this technique is of sufficient accuracy to illustrate the relative direction and magnitude of the impedance changes accompanying spiking. In all, 274 resistance measurements on 42 spikes were correlated with their pre- and postspike time of occurrence (10 different DA cells in 10 rats were used). The relative resistance changes observed suggest that little input resistance change occurs during the slow depolarization; however, a significantly large input resistance decrease is observed during the AHP which follows the spike (Fig. 8). This AHP is described in more detail below.

Afterhyperpolarization. The AHP is a negative shift in the membrane potential accompanied by spike inhibition, and it occurs following single or multiple spikes. Furthermore, if a 100 - to 200 -msec depolarizing current pulse of sufficient amplitude to trigger action potentials is injected intracellularly into DA neurons, a rebound hyperpolarization is observed at the termination of the pulse. This spike-dependent hypcrpolarization is proportional to the number of spikes elicited, with a peak amplitude reached at about five spikes (Fig. 9). This AHP is of comparatively long duration, which can be estimated (from the average time required to return to prespike levels of input resistance) to be about $20 \mathrm{msec}$ following single spikes (from Fig. 8) and about 50 msec following a train of spikes (Fig. 10).

In many respects, this spike-dependent AHP observed in DA neurons resembles the calcium-activated potassium conductance $\left(I_{\mathrm{K}(\mathrm{Ca})}\right)$ observed in other preparations (Meech, 1978). The 
A

SPIKE THRESHOLO VARIABILITY

MEMBRANE POTENTIAL (mV)

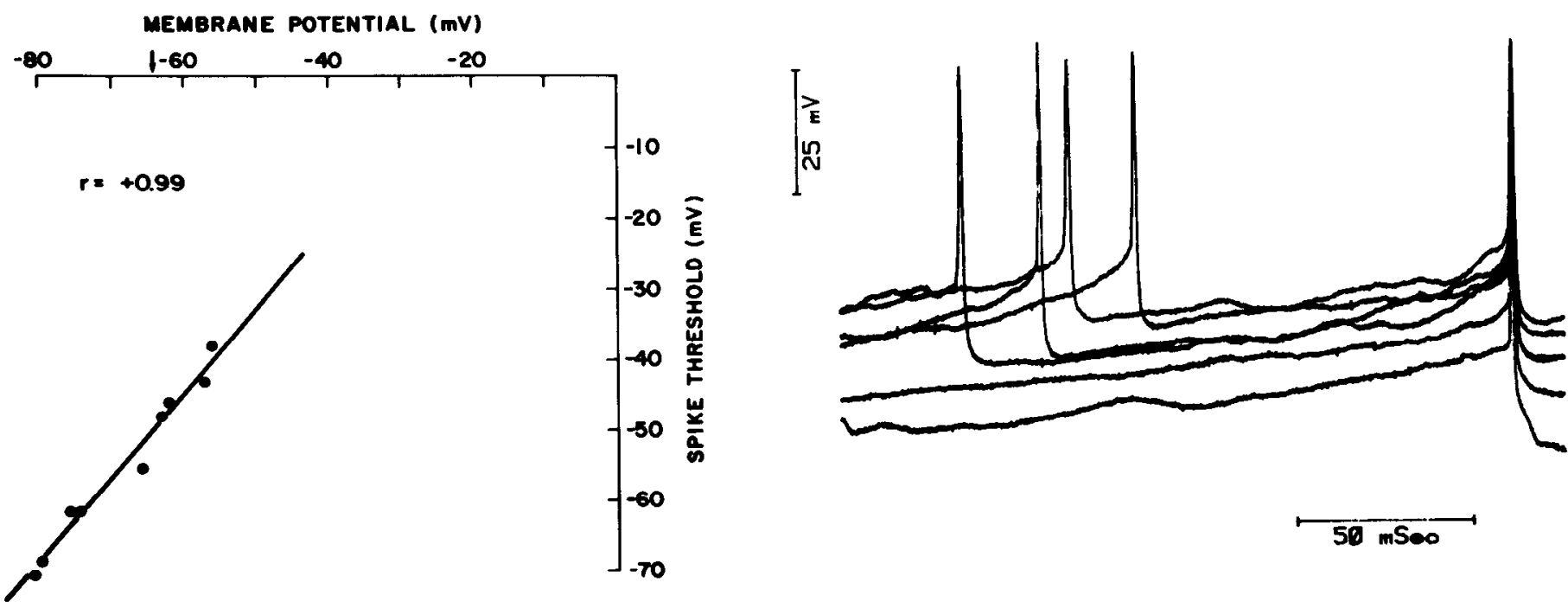

B

Figure 7. Effect of altering the membrane potential on the threshold of spontaneously occurring DA neuron spikes. A, As the DA neuron is depolarized, the increased rate of rise of the slow depolarization is partially offset by the increase in the threshold for spontaneous spike generation. Likewise, the injection of hyperpolarizing current caused the spike threshold to decrease. Resting membrane potential is indicated by an arrow. $B$, Oscilloscope tracing of superimposed action potentials recorded intracellularly at different membrane potentials. The membrane potential was altered by injecting hyperpolarizing or depolarizing current; bridge balance was confirmed throughout by injecting brief hyperpolarizing pulses (not shown). As the DA cell is depolarized, the DA cell slow depolarization increases its rate of rise. The threshold of the DA cell action potential also increases with depolarization. Action potentials at all membrane potentials reached the same peak amplitude (within 5 to $10 \mathrm{mV}$ ).

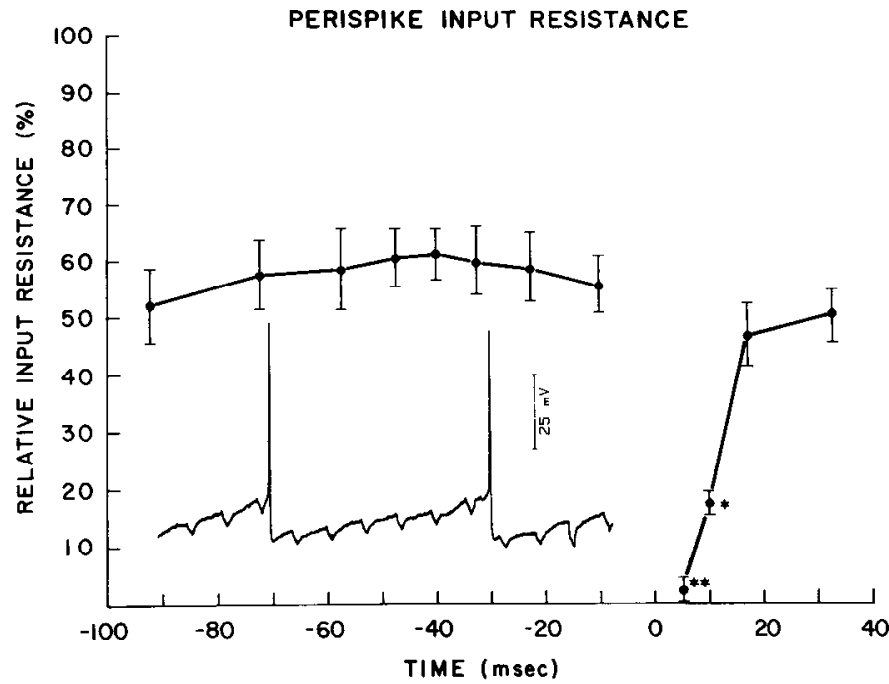

Figure 8. Estimate of the average relative input resistance changes occurring before and after a DA cell action potential. Short duration, low amplitude hyperpolarizing pulses were injected into DA cells and the membrane voltage deflections were recorded (as shown in the spike record). The relative input resistance (expressed as percentage of maximal input resistance change) is plotted against the time of measurement relative to the spike (spike occurs at $0 \mathrm{msec}$ ). Although little change in input resistance occurs during the slow depolarization prior to the action potential, there is a significant decrease in input resistance during the AHP relative to the prespike values. Time course of inset $=$ 350 msec. $*, p<0.05 ; * *, p<0.01$.

AHP following a spike train can be attenuated by intracellular injection of the calcium chelator EGTA $(N=6$; Fig. $11, A$ and $B)$, suggesting the involvement of calcium in its initiation. EGTA injection will also increase the amplitude of the DA cell action potential from its 65 - to $75-\mathrm{mV}$ amplitude in spontaneously discharging cells to up to $90 \mathrm{mV}$ in amplitude (Fig. $11 D)$. The ability of the potassium channel blocker tetraeth-

\section{AHP AMPLITUDE}

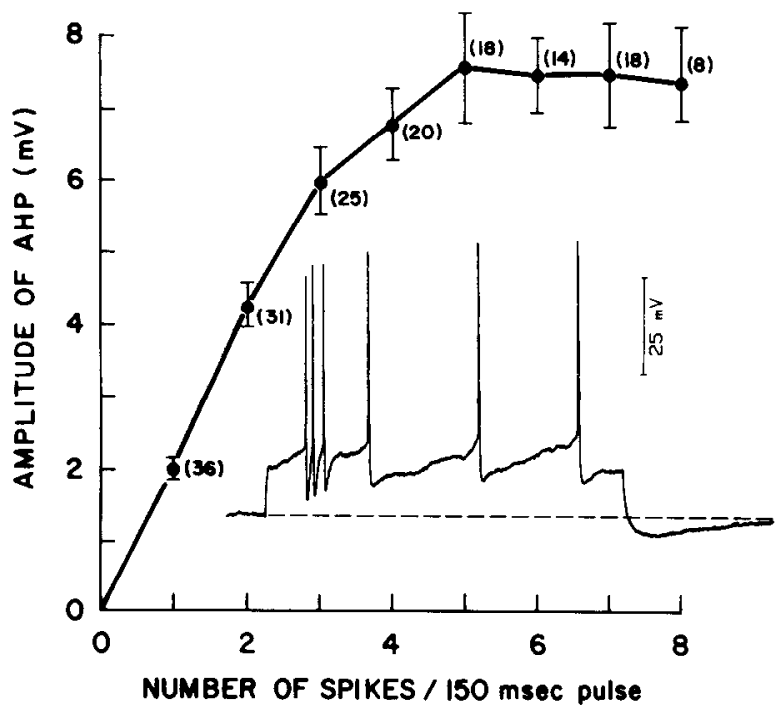

Figure 9. Dependence of spike train AHP amplitude on the number of spikes elicited. Intracellular injection of 150 -msec depolarizing current pulses of different amplitudes resulted in a series of one to eight spikes in DA neurons. At the termination of the pulse, an AHP was observed (a typical response is illustrated). 'The amplitude of the AHP was found to be proportional to the number of spikes evoked during the current pulse. A plateau amplitude of about $8 \mathrm{mV}$ was reached with trains of five to six spikes. Numbers in parentheses represent the number of spike trains of the specified length which were used to obtain the value specified. Values are expressed as mean \pm SEM.

ylammonium (TEA) to block this current (see Fig. 14 in Grace and Bunney, 1984b) lends further support to this origin of the AHP.

The involvement of this AHP in the modulation of DA cellfiring pattern was further explored by studying depolarizationelicited repetitive firing. DA cells have a linear relationship 
AHP DURATION

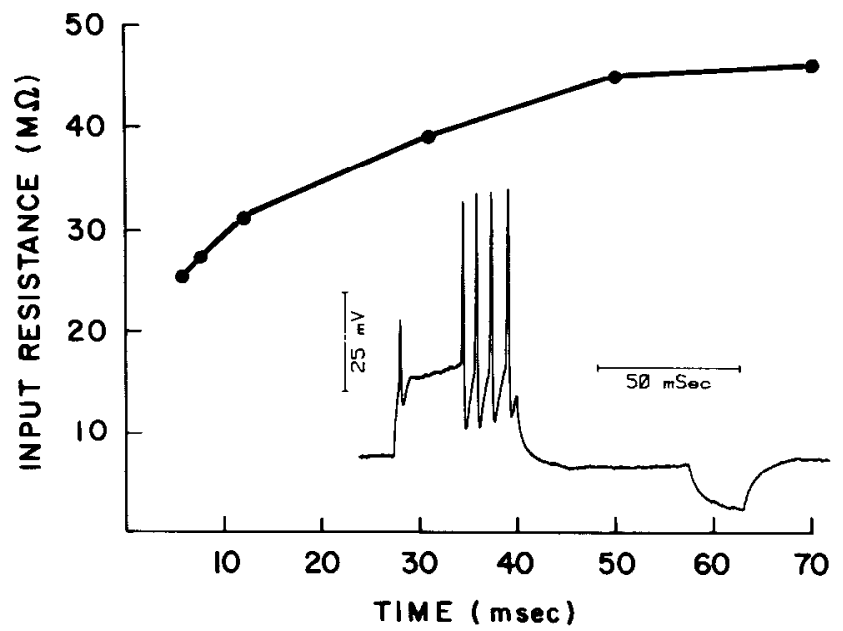

Figure 10. Duration of AHP following a train of spikes. The input resistance of DA cells was observed to decrease for the first $50 \mathrm{msec}$ following a train of spikes elicited by depolarizing current injection (a typical response is illustrated). between the amplitude of the depolarizing current pulses injected and the number of spikes elicited ( $N=6$; Fig. 12$)$. Closer examination of the multiple elicited spikes reveals that each successive spike occurs with an increased interspike interval, associated with a slower-rising slow depolarization. A sequence of depolarization-elicited spikes obtained during EGTA injection reveals quite a different picture. The number of spikes elicited by constant amplitude depolarizing pulses increases with time as EGTA leaks from the recording electrode into the impaled cell ( $N=6$; Fig. 13$)$. Perhaps more importantly, the interspike interval between the spikes remains constant, with the slow depolarization rising at nearly equal rates for all spikes. Furthermore, the spontaneous firing pattern gradually changes during EGTA injection to resemble a characteristic even-firing

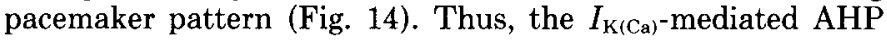
appears to regulate DA neuron single spike firing by producing rapid accommodation to short excitations, as well as modulating the pacemaker pattern produced by the slow depolarization into the characteristically observed irregular firing pattern.

\section{Discussion}

DA neurons in the substantia nigra of anesthetized or paralyzed rats can be either firing spontaneously (at rates typically
A

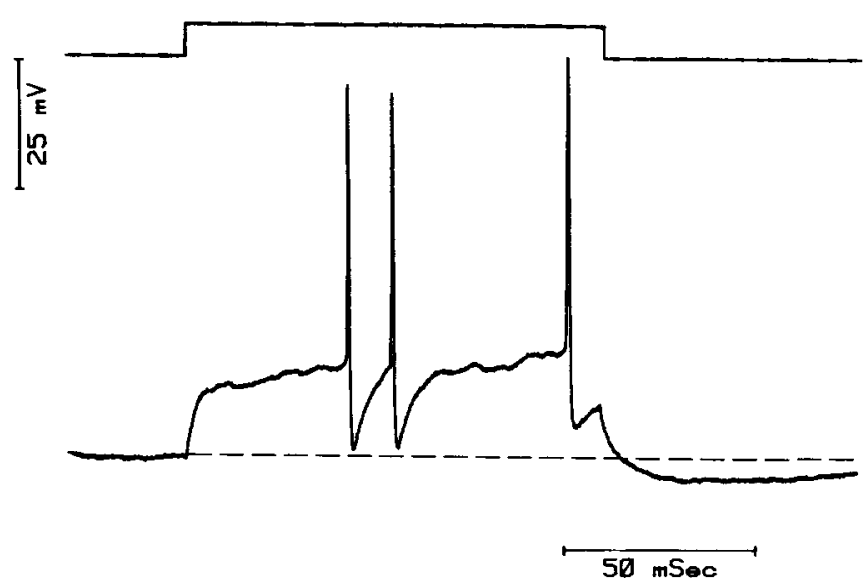

C

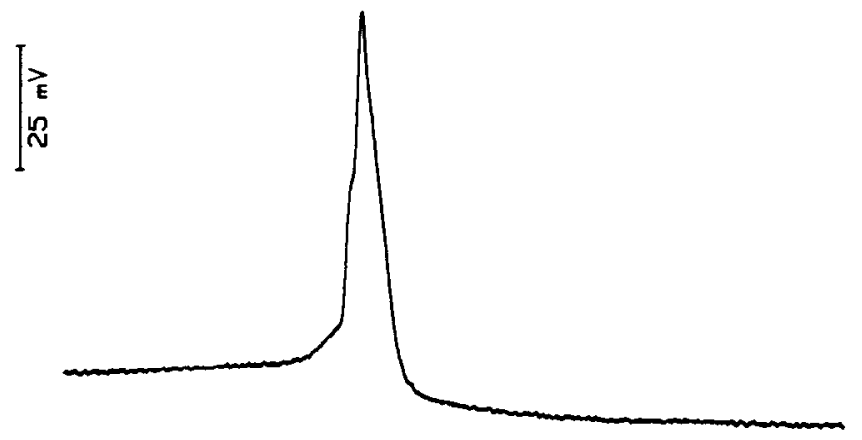

B

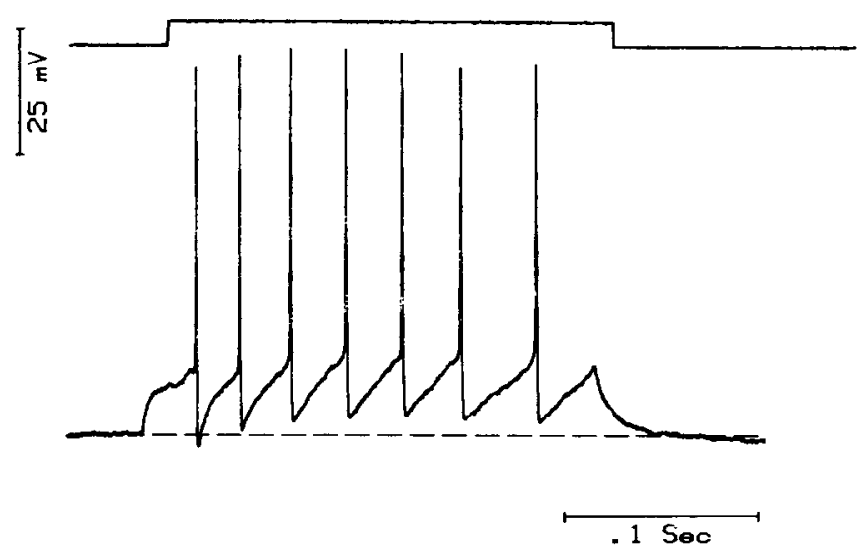

D

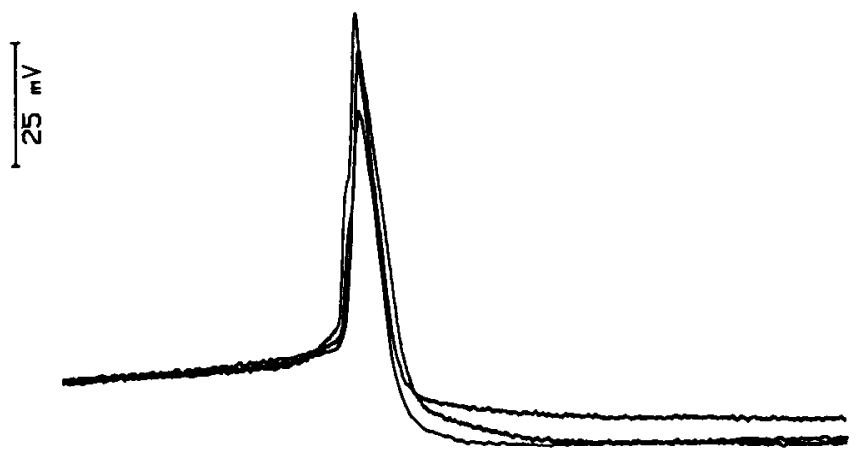

\section{$5 \mathrm{mSeo}$}

Figure 11. Effects of intracellular EGTA injection on DA neuron spike-generating properties. A, Typical response of untreated DA neuron to intracellular injection of $0.6 \mathrm{nA}$ of depolarizing current. Only a few spikes were elicited at irregular intervals. A prominent AHP at the termination of the current pulse was observed. B, After intracellular injection of EGTA, a smaller amplitude $(0.45 \mathrm{nA})$ depolarizing current injection pulse resulted in seven equally spaced, large amplitude action potentials. No AHP could be observed at the termination of the depolarizing current pulse. $C$, Large amplitude $(90 \mathrm{mV})$ DA cell action potential after longer periods of FGTA injection. $D$, Progressive changes in DA cell action potential shape during intracellular EGTA injection. A progressive increase in amplitude accompanied by a longer delay in the repolarization of the membrane potential was observed with prolonged periods of EGTA injection (total injection time $=45 \mathrm{~min}$ ). 


\section{CURRENT-INDUCED SPIKE GENERATION}

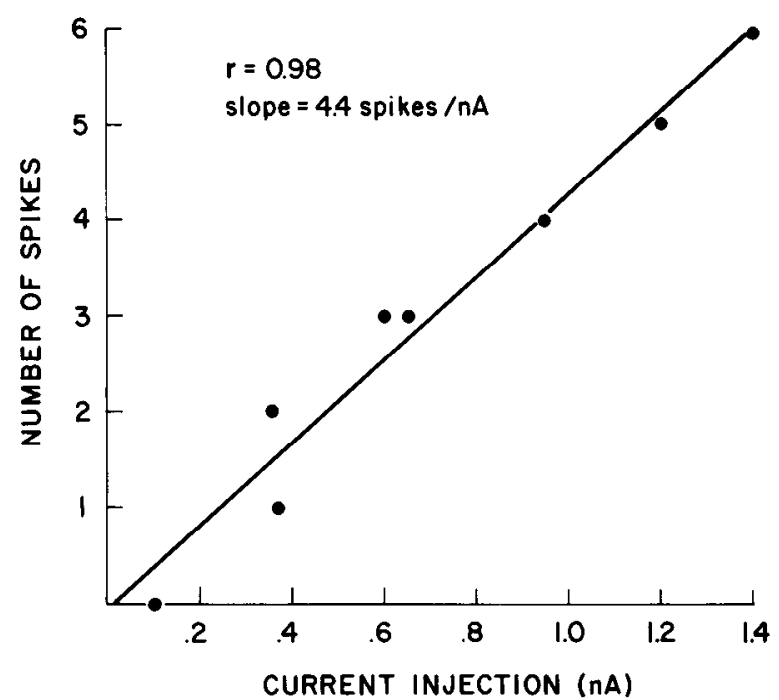

Figure 12. Dependence of the number of spikes elicited in DA neurons by a 150 -msec current pulse on the amplitude of the current injected. A linear relationship between the number of spikes elicited and the intensity of the depolarizing stimulus was found. Deviations from linearity were found primarily during lower levels of current injection, since the coincidence of the pulse with a spontaneously occurring slow depolarization was a more important factor in determining whether spiking would occur than was the absolute level of the current injected at these intensities.

above $2 \mathrm{~Hz}$ ) or nonfïring. At least $30 \%$ of the DA cells sampled electrophysiologically have been found to be inactive in chloral hydrate-anesthetized or gallamine-paralyzed rats (Bunney and Grace, 1978; Chiodo and Bunney, 1983; White and Wang, 1983). In contrast, very slow-firing DA cells (i.e., less than 1 $\mathrm{Hz}$ ) were rarely encountered. Although the reasons for not encountering DA cells firing within this frequency range are unclear, the finding that $\mathrm{DA}$ cells tend to release more dendritic DA as their firing rate slows (Nieoullon et al., 1977, 1978; Chèramy et al., 1978, 1981; Nieoullon and Dusticier, 1980) may be a contributing factor to this phenomenon. Thus, slowly firing DA cells would be expected to release more DA locally and, through feedback onto autoreceptors, to self-inhibit their own firing so as to cause complete cessation of firing. This, however, remains to be substantiated experimentally. Firing can be initiated in previously nonfiring cells through excitation induced by glutamate iontophoresis (Fig. 1), cholecystokinin iontophoresis (Skirboll et al., 1981), and intravenous haloperidol administration (Bunney and Grace, 1978). When DA cells are spontaneously active, they typically fire at a rather slow rate of about 4 to 5 spikes/sec. Two firing patterns have been observed in these neurons: (1) a slow, irregular pattern, and (2) burst firing. In analyzing nonburst-firing cells, the irregular single spike firing pattern was found to arise from the alternation of two transmembrane currents: (1) a voltage-dependent, slow, pacemaker-like depolarization preceding the action potential, and (2) an AHP following the action potential, arising from a spike-dependent $I_{\mathrm{K}(\mathrm{Ca}) \text {. }}$

Slow depolarization. A distinguishing characteristic of DA neuron spontaneous spike discharge observed during intracellular recording is the slow depolarization preceding action potentials (Grace and Bunney, 1983a, b). The slow depolarization apparently drives spiking in DA cells, since EPSPs were never observed to occur spontaneously in DA neurons recorded intracellularly. These slow potentials appear to be voltage dependent, since: (1) they can be activated by subthreshold depolarizing pulses, (2) they can be inactivated or "reset" by brief hyperpolarizing pulses, and (3) their rate of rise is proportional to the membrane potential. Hyperpolarizing DA neurons, by as much as $20 \mathrm{mV}$ from the resting potential, will slow the rate of rise of this potential but typically will not totally block its occurrence. Apomorphine, on the other hand, does completely inactivate this current (Grace and Bunney, 1982, 1983a, 1984a).

This slow depolarization has a number of characteristics in common with pacemaker potentials. Its pacemaker property is revealed when the $I_{\mathrm{K}(\mathrm{Ca})}$ is blocked by EGTA, a treatment which causes DA cells to fire in a very regular pattern. Pacemaker currents have been reported in both vertebrate and invertebrate preparations. In the molluscs Helix and Aplysia, a slow inward pacemaker current has been characterized as leading to burst discharge (Wilson and Wachtel, 1974, 1978). This current consists of a voltage-dependent sodium current in Aplysia (Smith et al., 1975; Barker and Smith, 1978; Carnevale and Wachtel, 1980; Carpenter and Gunn, 1980; Colmers et al., 1982) and a voltage-dependent sodium and calcium current in Helix (Eckert and Lux, 1976; Heyer and Lux, 1976; Ehile and Gola, $1979 a, b)$. This current is regenerative over a narrow voltage range. Depolarizing pulses which bring the membrane potential into this range activate the slow depolarization; hence, depolarizing current pulses result in voltage deflections of greater amplitude than those obtained with hyperpolarizing pulses due to activation of this current (Stafstrom et al, 1982). This region of membrane voltage instability can be observed in the steadystate current/voltage plots obtained during voltage clamping as a region of negative slope conductance (Gola, 1974; Wilson and Wachtel, 1974, 1978; Eckert and Lux, 1976; Johnston, 1976; Gorman et al., 1982; Stafstrom et al., 1982).

In vertebrate nervous systems, slow depolarization arising from inward currents have been reported in hippocampal pyramidal cells (Johnston et al., 1980; Brown and Griffith, 1983), neocortical pyramidal cells (Stafstrom et al., 1982), and cerebellar Purkinje cells (Llinàs and Sugimori, 1980a, b). In the raphe nucleus, however, pacemaker currents have been proposed to arise from a decay in the $I_{\mathrm{K}(\mathrm{Ca})}$ rather than being derived from an inward current source (Aghajanian and Vandermaelen, 1982a). In contrast, in DA neurons the slow depolarization is clearly a separate phenomenon from the AHP, since (1) the decrease in conductance occurring during the AHP does not continue during the slow depolarization, (2) the slow depolarization can be triggered by depolarizing current injection and can be inhibited by hyperpolarizing current injection, and (3) a slow depolarization can occur hundreds of milliseconds after a previous spike in a slowly firing DA cell. In some vertebrate brain regions, the slow inward pacemaker current appears to be a sodium current, due to its blockade by tetrodotoxin in the neocortex (Stafstrom et al., 1982) and in the cerebellum (Llinàs and Sugimori, 1980a, b), although its sensitivity to external calcium blockers in the hippocampus (Johnston et al., 1980; Brown and Griffith, 1983) indicates that it may be calcium mediated in this brain region.

Since little resistance change occurs during the slow depolarization in DA cells, it is probably also derived from a slow inward current. Thus, the slow depolarization which triggers single spikes in DA neurons has many characteristics in common with slow, inward pacemaker currents as described in other preparations. However, it has not yet been determined whether this current is sodium or calcium mediated in DA cells. Afterhyperpolarization. The AHP following DA neuron action potentials and depolarization-elicited trains of spikes is most likely the $I_{\mathrm{K}(\mathrm{Ca})}$, due to its demonstrated dependence on somatodendritic (SD) spike activation and blockade by EGTA and TEA. This current was first discovered in red blood cells (Gàrdos, 1958) and has since been reported in a number of 

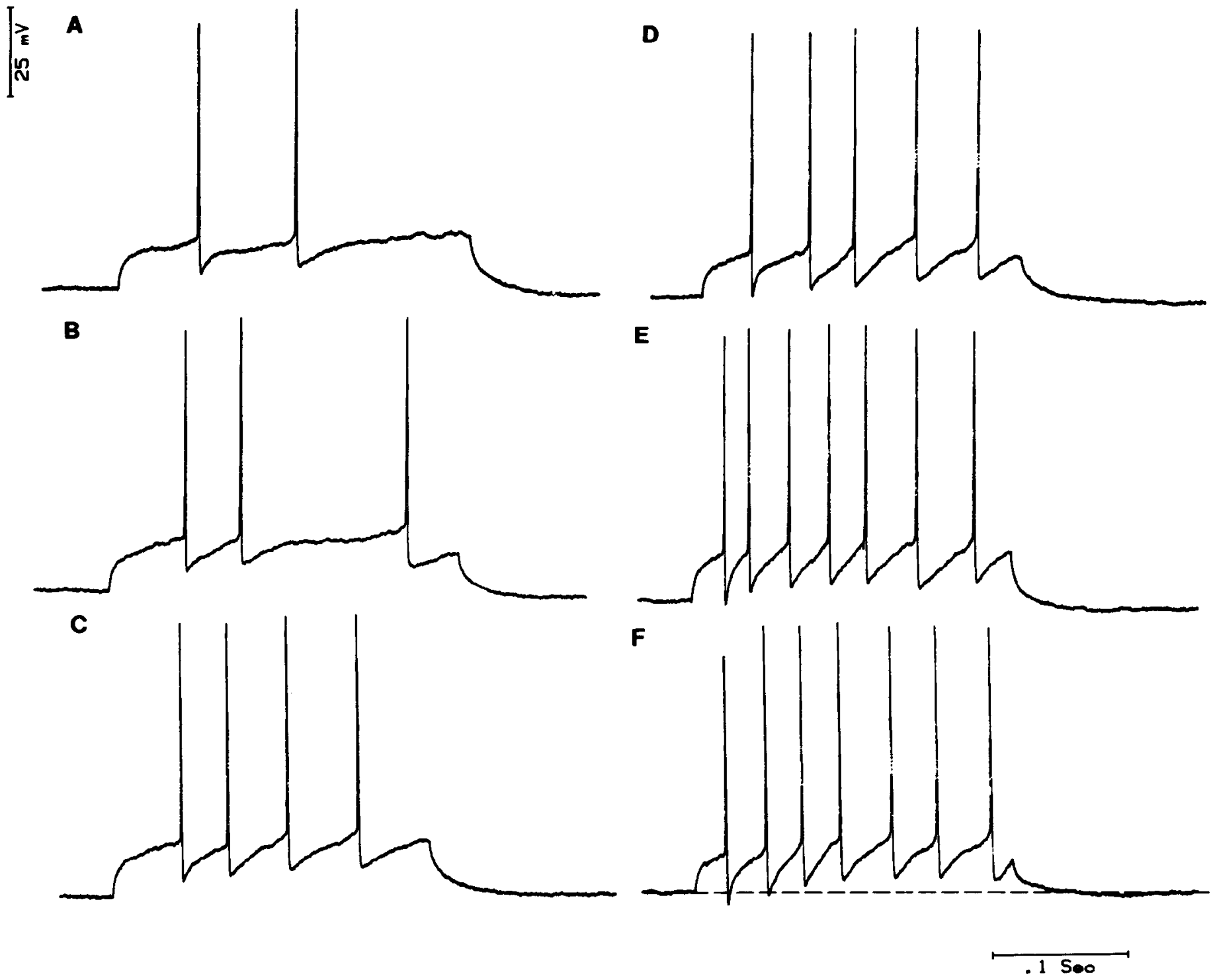

Figure 13. Effects of increasing levels of intracellular EGTA on the spiking pattern produced by a low amplitude $(0.42 \mathrm{nA})$ constant current pulse. $A$ to $F$, As EGTA was leaked into the DA cell from the microelectrode, the number of spikes elicited by the depolarizing pulse increased from two spikes $(A)$ to seven spikes $(F)$. In addition, the spikes fired in a more regular, pacemaker like manner with increasing levels of intracellular EGTA. The AHP demonstrated a progressive decrease in amplitude, until it completely inactivated with longer periods of EGTA injection (dashed line in $F$ ).

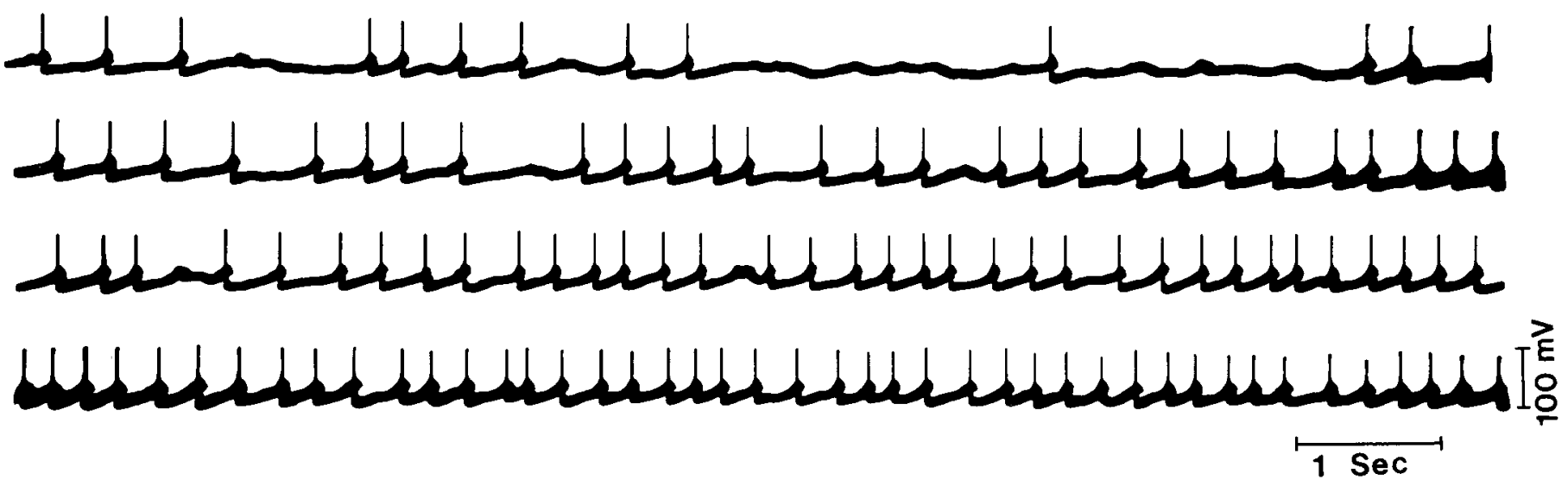

Figure 14. Effects of EGTA injected intracellularly on the firing pattern of DA cells. Within minutes after impalement and stabilization of a DA neuron with an EGTA-containing electrode, the DA cell demonstrates its typical slow, irregular firing pattern (top trace). As EGTA diffuses into the cell, this firing pattern gradually changes into a very regular, pacemaker-like pattern (second through fourth tracings). This process requires approximately 15 to $20 \mathrm{~min}$ after initial impalement for the pacemaker pattern to arise. 
vertebrate (Hotson and Prince, 1980; Llinàs and Sugimori, 1980a, b; Llinàs and Yarom, 1981a, b; Aghajanian and Vandermaelen, 1982a, b; Aghajanian et al., 1983) and invertebrate (Meech, 1972; Meech and Standen, 1975; Heyer and Lux, 1976; Adams and Gage, 1979a, b, c, 1980; Aldrich et al., 1979; Gorman and Herman, 1979) preparations. The AHP delays the onset of the next action potential in a train. This delay is probably due to a combination of the increased membrane conductance and the voltage-dependent inactivation of the slow depolarization occurring during the AHP, thus effectively "shorting out" the slow depolarization. Thus, this AHP may temporarily inactivate the spontaneous slow depolarization and thereby increase the interspike interval in spike trains. This inhibitory period can be greatly attenuated by intracellular administration of the calcium chelator EGTA.

Intracellular injection of EGTA also affects the amplitude of the DA cell action potential. Spontaneously discharging DA cells have an amplitude of 60 to $70 \mathrm{mV}$ when recorded intracellularly. Hyperpolarizing DA cells by current injection slows their firing rate, causing the action potential amplitude to rise above $75 \mathrm{mV}$. This increase in amplitude with a decrease in firing rate can also be observed with intravenous apomorphine(Grace and Bunney, 1983a) or iontophoretic GABA-induced (Aghajanian and Bunney, 1977) inhibition of DA cell firing rate when recording extracellularly. Intracellular injection of the calcium chelator EGTA increases the amplitude of DA cell action potentials even further, with spontaneously occurring action potentials occasionally overshooting $90 \mathrm{mV}$. Action potentials of this amplitude were never observed in a spontaneously firing DA cell, even with penetrations stable enough to permit intracellular recordings of spontaneously active DA cells for periods of $2 \mathrm{hr}$ or more. Although the mechanism by which EGTA will increase the amplitude of the DA cell action potential cannot be determined conclusively using the techniques described here, one possibility may be that EGTA is removing a residual calcium-induced inactivation of the calcium current associated with the SD portion of the action potential. In other preparations EGTA has been shown to increase the peak inward calcium current during action potential generation by as much as $30 \%$, due to removal of calcium current inactivation (Eckert and Tillotson, 1982; Plant et al., 1983). Likewise, intracellular injection of calcium has been found to lead to an inactivation of voltage-dependent calcium currents (Kostyuk and Krishtal, 1977; Brehm and Eckert, 1978; Tillotson, 1979; Brehm et al., 1980; $\Lambda$ scheroft and Stanfield, 1981; Brown et al., 1981; Eckert and Tillotson, 1981; Marban and Tsien, 1981; Plant and Standen, 1981a, b; Plant et al., 1983). This mechanism may also be partially responsible for the increased action potential amplitude observed in DA neurons after intracellular EGTA administration. Thus, the DA neuron SD spike amplitude may decrease rapidly during increased firing rates secondary to the greater calcium influx accompanying the increased number of spikes. 'I'he initial segment spike (which is most likely sodium mediated), on the other hand, maintains the same amplitude throughout this depolarization (Grace and Bunney, $1983 \mathrm{~b})$. As DA neurons are known to show wide variations in their action potential duration and amplitude with increases or decreases in firing rate, a significant amount of calcium channel inactivation may be present in untreated, normally firing DA cells. Of course, a shift in the SD spike initiation site away from the soma can also result in a similar phenomenon, and further work is required to sort out the contributions of these and other mechanisms to the observed changes in spike amplitude.

The AHP in DA cells also appears to be involved in the modulation of DA cell-firing pattern; specifically, in the rapid accommodation found in response to brief periods of excitation. This accommodation can be attenuated by intracellular injec- tion of EGTA, as has also been shown in another monoamine cell group, the locus ceruleus (Aghajanian et al., 1983). The resultant firing pattern then appears to be determined only by the slow depolarization. Under these conditions, spikes are equally spaced temporally and arise from faster rising slow depolarizations, thus closely resembling the firing pattern of pacemaker cells as described in invertebrates (Gorman et al., 1982) and in the mammalian raphe nucleus (Aghajanian and Vandermaelen, 1982a). Furthermore, in the in vitro nigral slice preparation, decreasing calcium concentrations in the bathing medium will also cause DA cells to fire in a pacemaker-like pattern (Sanghera et al., 1983). Our data suggest that an $I_{\mathrm{K}(\mathrm{Cu})}$ may be involved in the rapid accommodation of firing rate in DA cells in response to a brief depolarizing stimulus.

Thus, DA neuron spike generation appears to occur in a manner similar to that involved in the pacemaker cycle described in various invertebrate preparations (Gola, 1974; Gola et al., 1977; Gorman and Hermann, 1982; Gorman and Thomas, 1978, 1980; Gorman et al., 1982). Of course, these basic mechanisms of DA cell firing will be further modulated by the actions of neurotransmitters impinging on these cells. In the next paper (Grace and Bunney, 1984h), additional data are presented to explain the transition of DA neurons from the single spike mode into burst firing.

\section{References}

Adams, D. J., and P. W. Gage (1979a) Ionic currents in response to membrane depolarization in an Aplysia neuron. J. Physiol. (Lond.) 289: $115-141$.

Adams, D. J., and P. W. Gage (1979b) Characteristics of sodium and calcium conductance changes produced by membrane depolarization in an Aplysia neurone. J. Physiol. (Lond.) 289: 143-161.

Adams, D. J., and P. W. Gage (1979c) Sodium and calcium gating currents in an Aplysia neurone. J. Physiol. (Lond.) 291: 467-481.

Adams, D. J, and P. W. Gage (1980) Divalent ion currents and the delayed potassium conductance in an Aplysia neurone. J. Physiol. (Lond.) 304: 297-313.

Aghajanian, G. K., and B. S. Bunney (1977) Dopamine "autoreceptors": Pharmacological characterization by microiontophoretic single unit recording studies. Naunyn Schmiedebergs Arch. Pharmacol. 297: 17.

Aghajanian, G. K., and C. P. Vandermaelen (1982a) Intracellular recordings from serotonergic dorsal raphe neurons: Pacemaker potentials and the effects of LSD. Brain Res. 238: 463-469.

Aghajanian, G. K., and C. P. Vandermaelen (1982b) Alpha-2-adrenoceptor-mediated hyperpolarization of locus coeruleus neurons: Intracellular studies in vivo. Science 215: 1394-1396.

Aghajanian, G. K., C. P. Vandermaelen, and R. Andrade (1983) Intracellular studies on the role of calcium in regulating the activity and reactivity of locus coeruleus neurons in vivo. Brain Res. 273: 237243.

Aldrich, R. W., P. A. Getting, and S. H. Thompson (1979) Inactivation of delayed outward current in molluscan neurone somata. J. Physiol. (Lond.) 291: 507-530.

Aschcruft, F. M., and P. R. Stanfield (1981) Calcium dependence of the inactivation of calcium currents in skeletal muscle fibers of an insect. Science 213: 224-226.

Barker, J. L., and T. G. Smith (1978) Electrophysiological studies of molluscan neurons generating bursting pacemaker potential activity. In Abnormal Neuronal Discharges, N. Chalazonitis and M. Boisson, eds., pp. 359-387, Raven Press, New York.

Bloom, F. E. (1974) To spritz or not to spritz: The doubtful value of aimless iontophoresis. Life Sci. 14: 1819-1843.

Braszko, J. J., M. J. Bannon, B. S. Bunney, and R. H. Roth (1981) Intrastriatal kainic acid: Acute effects on electrophysiological and biochemical measures of nigrostriatal dopaminergic activity. J. Pharmacol. Exp. Ther. 216: 289-293.

Brehm, P., and R. E. Eckert (1978) Calcium entry leads to inactivation of calcium channel in Paramecium. Science 202: 1203-1206.

Brehm, P., R. E. Eckert, and D. Tillotson (1980) Calcium-mediated inactivation of calcium current in Paramecium. J. Physiol. (Lond.) 306: 193-203. 
Brown, A. M., K. Morimoto, Y. Tsuda, and D. L. Wilson (1981) Calcium current-dependent and voltage-dependent inactivation of calcium channels in Helix aspersa. J. Physiol. (Lond.) 320: 193-218.

Brown, D. A., and W. H. Griffith (1983) Persistent slow inward calcium current in voltage-clamped hippocampal neurones of the guinea-pig. J. Physiol. (Lond.) 337: 303-320.

Bunney, B. S., and A. A. Grace (1978) Acute and chronic haloperidol treatment: Comparison of effects on nigral dopaminergic cell activity. Life Sci. 23: 1715-1728.

Bunney, B. S., J. R. Walters, R. H. Roth, and G. K. Aghajanian (1973) Dopaminergic neurons: Effect of antipsychotic drugs and amphetamine on single cell activity. J. Pharmacol. Exp. Ther. 185: 560-571.

Carnevale, N. T., and H. Wachtel (1980) Two reciprocating current components underlying slow oscillations in Aplysia bursting neurons. Brain Res. Rev. 2: 45-68.

Carpenter, D. O., and R. Gunn (1970) The dependence of pacemaker discharge of Aplysia neurons upon $\mathrm{Na}^{+}$and $\mathrm{Ca}^{++}$. J. Cell Physiol. 75 : 121-128.

Chèramy, A., A. Nieoullon, and J. Glowinski (1978) In vivo changes in dopamine release in cat caudate nucleus and substantia nigra induced by nigral application of various drugs including GABAergic agonists and antagonists. In Interactions Between Putative Neurotransmitters in the Brain, S. Garattini, J. F. Pujol, and R. Samanin, eds., pp. 175190, Raven Press, New York.

Chèramy, A., V. Leviel, and J. Glowinski (1981) Dendritic release of dopamine in the substantia nigra. Nature 289: 537-542.

Chiodo, L. A., and B. S. Bunney (1983) Typical and atypical neuroleptics: Differential effects of chronic administration on the activity of A9 and A10 midbrain dopaminergic neurons. J. Neurosci. J. 3: 16071619.

Colmers, W. F., D. V. Lewis, and W. A. Wilson (1982) $\mathrm{Ca}^{+}$loading reveals $\mathrm{Na}^{+}$-dependent persistent inward current and negative slope resistance region in Aplysia giant neurons. J. Neurophysiol. 48: 11911200 .

Eckert, R., and H. D. Lux (1976) A voltage-sensitive persistent calcium conductance in neuronal somata of Helix. J. Physiol. (Lond.) 254. $129-151$

Eckert, R., and T. L. Tillotson (1981) Calcium-mediated inactivation of the calcium conductance in caesium-loaded giant neurones of Aplysia californica. J. Physiol. (Lond.) 314: 265-280.

Ehile, E., and M. Gola (1979a) A slowly inactivating calcium current in molluscan neurons. I. Slow currents during long-lasting voltage clamp pulses. Comp. Biochem. Physiol. A 64: 213-223.

Ehile, E., and M. Gola (1979b) A slowly inactivating calcium current in molluscan neurons. II. Kinetics and steady-state properties. Comp. Biochem. Physiol. A. 64: 225-234.

Gardos, G. (1958) The function of calcium in the potassium permeability of human erythrocytes. Biochim. Biophys. Acta 30: 653-654.

Gola, M. (1974) Neurones à ondes-salves des mollusques. Pflügers Arch. 352: 17-36.

Gola, M., C. Ducreaux, and H. Chagneux (1977) Ionic mechanism of slow potential wave production in barium-treated Aplysia neurons. J. Physiol. (Paris) 73: 407-440.

Gorman, A. L. F., and A. Hermann (1979) Internal effects of divalent cations on potassium permeability in molluscan neurons. J. Physiol. (Lond.) 296: 393-410.

Gorman, A. L. F., and A. Hermann (1982) Quantitative differences in the currents of bursting and beating molluscan pace-maker neurons. J. Physiol. (Lond.) 333: 681-699.

Gorman, A. L. F., and M. V. Thomas (1978) Changes in the intracellular concentration of free calcium ions in a pace-maker neurone, measured with the metallochromic indicator dye Arsenazo III. J. Physiol. (Lond.) 275: 357-376

Gorman, A. L. F., and M. V. Thomas (1980) Potassium conductance and internal calcium accumulation in a molluscan neuron. J. Physiol. (Lond.) 308: 287-313

Corman, A. L. F., A. Hermann, and M. V. Thomas (1982) Ionic requirements for membrane oscillations and their dependence on the calcium concentration in a molluscan pace-maker neurone. J. Physiol. (Lond.) 327: 185-217.

Grace, A. A., and B. S. Bunney (1979) Paradoxical GABA excitation of nigral dopaminergic cells: Indirect mediation through reticulata inhibitory neurons. Eur. J. Pharmacol. 59: 211-218.

Grace, A. A., and B. S. Bunney (1980) Nigral dopamine neurons: Intracellular recording and identification using $\mathbf{L}$-DOPA injection combined with fluorescence histochemistry. Science 210: 654-656.

Grace, A. A., and B. S. Bunney (1982) Intracellular studies of nigral dopamine neurons: Morphology, action potential generation, and effects of apomorphine. Soc. Neurosci. Abstr. 8: 481

Grace, A. A., and B. S. Bunney (1983a) Intracellular and extracellular electrophysiology of nigral dopaminergic neurons. I. Identification and characterization. Neuroscience 10:301-315.

Grace, A. A., and B. S. Bunney (1983b) Intracellular and extracellular electrophysiology of nigral dopaminergic neurons. II. Action potential generating mechanisms and morphological correlates. Neuroscience 10:317-331.

Grace, A. A., and B. S. Bunney (1983c) Single spiking and burst firing in nigral dopamine neurons. Soc. Neurosci. Abstr. 9: 1006.

Grace, A. A., and B. S. Bunney (1984a) Nigral dopamine neurons: Extracellular and intracellular electrophysiological characteristics. In Catecholamines. Neuropharmacology and Central Nervous System-Theoretical Aspects, E. Usdin, A. Carlsson, A. Dahlström, and J. Engel, ed., pp. 323-332, Alan R. Liss, Inc., New York.

Grace, A. A., and B. S. Bunney (1984b) The control of firing pattern in nigral dopamine neurons: Burst firing. J. Neurosci. 4: 2877-2890.

Guyenet, P. G., and G. K. Aghajanian (1978) Antidromic identification of dopaminergic and other output neurons of the rat substantia nigra. Brain Res. 150: 69-84.

Heyer, C. B., and H. D. Lux (1976) Properties of a facilitating calcium current in pace-maker neurons of the snail, Helix pomatia. J. Physiol. (Lond.) 262: 319-348.

Hotson, J. R., and D. A. Prince (1980) A calcium-activated hyperpolarization follows repetitive firing in hippocampal neurons. J. Neurophysiol. 43: 409-419.

Johnston, D. (1976) Voltage clamp reveals basis for calcium regulation of bursting pacemaker potential in Aplysia neurons. Brain Res. 107: $418-423$.

Johnston, D., I. .J. Hablitz, and W. A. Wilson (1980) Voltage clamp discloses slow inward current in hippocampal burst-firing neurones. Nature 286: 391-393.

König, R., and R. A. Klippel (1970) The Rat Brain: A Stereotaxic Atlas, Krieger Publishing Co., New York.

Kostyuk, P. G., and O. A. Krishtal (1977) Effects of calcium and calcium-chelating agents on the inward and outward current in the membrane of mollusc neurones. J. Physiol. (Lond.) 270: 569-580.

Llinàs, R., and M. Sugimori (1980a) Electrophysiological properties of in vitro Purkinje cell somata in mammalian cerebellar slices. J. Physiol. (Lond.) 305: 171-195.

Llinàs, R., and M. Sugimori (1980b) Electrophysiological properties of in vitro Purkinje cell dendrites in mammalian cerebellar slices. J. Physiol. (Lond.) 305: 197-213.

Llinàs, R., and Y. Yarom (1981a) Electrophysiology of mammalian inferior olivary neurones in vitro. Different types of voltage-dependent ionic conductances. J. Physiol. (Lond.) 315: 549-567.

Llinàs, R., and Y. Yarom (1981b) Properties and distribution of ionic conductances generating electroresponsiveness of mammalian inferior olivary neurones in vitro. J. Physiol. (Lond.) 315: 569-584.

Marban, E., and R. W. Tsien (1981) Is the slow inward calcium current of heart muscle inactivated by calcium? Biophys. J. 33: 143a.

Meech, R. W. (1972) Intracellular calcium injection causes increased potassium conductance in Aplysia nerve cells. Comp. Biochem. Physiol. 42A: 493-499.

Meech, R. W. (1978) Calcium-dependent potassium activation in nervous tissues. Annu. Rev. Biophys. Bioeng. 7: 1-18.

Meech, R. W., and N. B. Standen (1975) Potassium activation in Helix aspersa neurones under voltage clamp: A component mediated by calcium influx. J. Physiol. (Lond.) 249: 211-239.

Nieoullon, A., and N. Dusticier (1980) Changes in dopamine release in caudate nuclei and substantia nigrae after electrical stimulation of the posterior interposate nucleus of cat cerebellum. Neurosci. Lett. 17: $167-172$

Nieoullon, A., A. Chèramy, and J. Glowinski (1977) Nigral and striatal dopamine release under sensory stimuli. Nature 269: 340-342.

Nieoullon, A., A. Chèramy, and J. Glowinski (1978) Release of dopamine in both caudate nuclei and both substantia nigrae in response to unilateral stimulation of cerebellar nuclei in the cat. Brain Res. 148: $143-152$.

Plant, T. D., and N. B. Standen (1981a) Calcium current inactivation in Helix aspersa neurons studied using potassium current blockers. J. Physiol. (Lond.) 316: 4-5P. 
Plant, T. D., and N. B. Standen (1981b) Calcium current inactivation in identified neurones of Helix aspersa. J. Physiol. (Lond.) 321: 273285.

Plant, T. D., N. B. Standen, and T. A. Ward (1983) The effects of injection of calcium ions and calcium chelators on calcium channel inactivation in Helix neurons. J. Physiol. (Lond.) 334: 189-212.

Sanghera, M. K., M. E. Trulson, and D. C. German (1983) In vitro electrophysiological and pharmacological properties of midbrain dopamine neurons in the mouse. Soc. Neurosci. Abstr. 9: 1005.

Skirboll, L. R., A. A. Grace, D. W. Hommer, J. Rehfeld, M. Goldstein, T. Hökfelt, and B. S. Bunney (1981) Peptide-monoamine coexistence: Studies of the actions of cholecystokinin-like peptide on the electrical activity of midbrain dopamine neurons. Neuroscience 6 : 2111-2124.

Smith, T. G., J. L. Barker, and H. Gainer (1975) Requirements for bursting pacemaker potential activity in molluscan neurones. Nature 253: $450-452$

Stafstrom, C. E., P. C. Schwindt, and M. E. Crill (1982) Negative slope conductance due to a persistent subthreshold sodium current in cat neocortical neurons in vitro. Brain Res. 236: 221-226.

Tasaki, K., U. Tsukahara, S. Ito, M. J. Wayner, and W. Y. Yu (1968) A simple direct and rapid method for filling microelectrodes. Physiol. Behav. 3: 1009-1010.

Thomas, R. C., and V. J. Wilson (1965) Precise localization of Renshaw cells with a new marking technique. Nature 206: 211-214.

Tillotson, D. (1979) Inactivation of Ca conductance dependent on entry of Ca ions in molluscan neurons. Proc. Natl. Acad. Sci. U. S. A. 76: 1497-1500.

White, F. J., and R. Y. Wang (1983) Comparison of the effects of chronic haloperidol treatment on $\mathrm{A} 9$ and $\mathrm{A} 10$ dopamine neurons in the rat. Life Sci. 32: 983-993.

Wilson, W. A., and W. Wachtel (1974) Negative slope resistance characteristic essential for the maintenance of slow oscillations in bursting neurons. Science 186: 932-934.

Wilson, W. A., and H. Wachtel (1978) Prolonged inhibition in burst firing neurons: Synaptic inactivation of the slow regenerative inward current. Science 202: 772-775. 